\title{
A Sociolinguistic Study of the Horse Image in Some English and Iraqi Arabic Proverbs
}

\author{
Muhammed Barjes Salman ${ }^{1}$ Hassan Khalaf Amer ${ }^{2}$ \\ ${ }^{1}$ Department of English, College of Education for Humanities, Tikrit University, Tikrit, Iraq \\ ${ }^{2}$ Educational Directorate of Anbar, Al-Ramadi City, Anbar, Iraq
}

\begin{abstract}
This research deals with the horse image in some English and Iraqi Arabic proverbs showing how English and Iraqi Arabs interpret, understand, and use these proverbs which include horse image. The selected proverbs are analyzed depending on Holme's (2013) social factors which are: social distance variable, status variable and formality variable of setting. The English population of the research includes two universities in England. To make the project more applicable, the focus is on Leeds and London universities. The researcher chooses students randomly from "University of Leeds" in Leeds and a university named "London School of Economics and Political Sciences" in London. As for the Iraqi Arabic population, the people who represent the Arabic sample of the current study are from Tikrit and Anbar cities. They are enrolled at "Tikrit University" and "Anbar University" respectively. Among the findings, it is found out that English and Iraqi Arabs have somehow similar connotations concerning the horse image in relation to cultural, occupational, social distance, and formality variables. This denotes that though the two cultures are different, they share some social variables as they have similar connotations for some concepts as in the selected topic. The occupational variable shows that native speakers of both languages indicate that the proverbs which include the horse image are used more frequently by farmers other than other occupations.
\end{abstract}

KEY WORDS: Formality, Horse Image, Proverbs, Social Distance, Sociolinguistics, Status

\section{INTRODUCTION}

Proverbs are traditional sayings which play a very major role in the folklore of any culture. Many cultural themes can be found in proverbs because they are full of imagery (for example, animal, food, color, etc.). The range of animal images in proverbs is one of the most complicated one since it is important to understand the cultural value of the given animal to provide appropriate analysis, interpretation, and appropriate use of proverbs.

Koya University Journal of Humanities and Social Sciences (KUJHSS),

Volume 3, Issue 1, 2020.

Received 28 April 2020; Accepted 07 June 2020,

Regular research paper: Published 16 June 2020

Corresponding author's e-mail: dijla1983@gmail.com

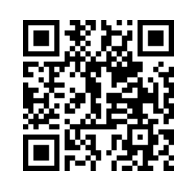

Copyright (C2020 Muhammed B. Salman \& Hassan KH.

Amer. This is an open access article distributed under the Creative Commons Attribution License.
Obviously, different people select diverse proverbs related to animals to cope with their social background and the demands of the social setting. In this respect, languages could contrastively display similarities or differences between the influences of social factors on the use of animal proverbs, for the same sake. Furthermore, animal proverbs show particular characteristics of people and their culture.

Consequently, this study is designed to address the problem that a language is not merely a simple means of communication used in the same way by all people. Obviously, language is used by speakers to mark their geographical and sociocultural factors of in accordance with the social context. In this regard, linguistic factors (that is, animal proverbs) can be correlated with nonlinguistic factors (that is, social factors). Typically, the choice of animal proverb is determined by many social factors. Besides, this study tackles the problem that the effects of different cultural values and the effects of occupational, social distance, and formality variables on 
linguistic choice of animal proverbs in English and Iraqi Arabic (IA) are diversified and problematic.

\section{HOLMES' VARIABLES} SOCIOLINGUISTIC

This study employs the sociolinguistic approach to the study of language. This approach proposes that both micro-sociolinguistic elements (such as social distance, social class, and formality) and macro-sociolinguistic elements (such as culture variable of connotation) influence language. Accordingly, in the analysis of data in both languages under investigation, we make use of the social dimensions model of linguistic communication developed notably by Holmes (2013) as the following subsections below:

\section{A. Social Distance Variable}

How well the speaker knows the addressee is a relevant factor in effecting linguistic choices a speaker makes (Holmes, 2013, p. 9). Determining what is appropriate in any speech community involves taking into consideration the solidarity (social distance) and the relative power (social status). Consequently, a language user needs to recognize the social value of any speech community for the sake of speaking appropriately and politely (Holmes, 2013, p. 285).

\section{B. Status Variable}

Holmes (2013, p. 10) clarifies the relationship between participants in terms of social status and their linguistic choice which would be appropriate. The status scale is shown in Fig. 1.

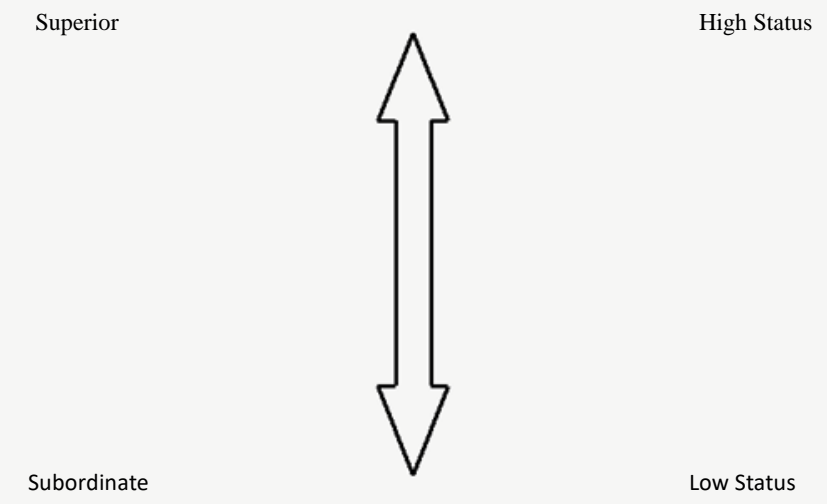

Fig. 1. The status scale (adopted from Holmes, 2013, p. 10).

Fig. 1 indicates that the superiority of a speaker in comparison with the addressee in the society is a relevant factor in linguistic choices. The superiority is due to various factors, among which are the speaker's belongingness to the high status, of older age, or due to his/her occupation. Consequently, the subordinate participant who belongs to the lower status will be careful in addressing the superior not to be viewed as rude or impolite (Holmes, 2013, p. 10).

When using linguistic expressions such as titles (for example, Dr.) in addressing someone, this reflects the speaker's awareness that the addressee is of higher status and entitled to a respect term (ibid: 10).

\section{Formality Variable of Setting}

The formality dimension accounts for the variation of speech in different social contexts. Formal settings such as law courts or a graduation ceremony and formal situations such as a formal interview with a bank manager or head teacher will require the choice of appropriate language expressions including proverbs. Although "solidarity and social status" are usually important in influencing appropriate language choice, the formality of the setting can sometimes override them (Holmes, 2013, p. 448). In courts, even brothers will call each other by their titles and other certain linguistic expressions that they use at home will not be used at court. This is because the language is prescribed by the formal setting more than by the closeness of their relationship (ibid: 448).

\section{POPULATION AND SAMPLE OF THE STUDY}

Population means any group of individuals that have one or more characteristics in common, whereas the sample means a small group from the population which is selected for experimental purposes (Best and Kahn, 2006, pp. 13-16).

The English population of the current study involves two universities in England. To make the project more applicable, the focus is on Leeds and London universities. The researcher chooses students randomly from "University of Leeds" in Leeds and a university named "London School of Economics and Political Sciences" in London, as the English sample of the current study. In sociolinguistics, it is difficult to involve the whole society under consideration; researchers usually take a small sample of informants to be representative of the whole society. It is just like the method adopted by Labov in his study of the relationship between social status and the pronunciation of the $/ \mathrm{r} /$ sound where his sample was selected randomly at selected stores. This small sample is considered by Labov as representative of the whole society, that is, Americans, especially New Yorkers (Yule, 2010, p. 256). Accordingly, this sample will be representative of the speech community of England.

As for the IA population, the people who represent the Arabic sample of the current study are from Tikrit and Anbar cities. They are enrolled at "Tikrit University" and "Anbar University," respectively. All these people have academic backgrounds and they are educated. The Iraqi people involved in this study 
usually speak heterogeneous dialects and they can also speak the standard Arabic if they like to.

\section{RESEARCH METHODOLOGY}

The present study uses both the qualitative and the quantitative methods. Before showing how these approaches are applied in the present study, it is worth mentioning the characteristics of these two methods. The qualitative method, on the one hand, uses fewer data with a deeper and detailed analysis. The quantitative method, on the other hand, uses numerical analysis and statistics. Moini (2008, p. 134) states that in qualitative research, few data are selected with a deep study of their dimensions. In quantitative research, on the other hand, a large sample is chosen for studying one or more aspects of the phenomenon.

Besides, in qualitative research, the results and reporting of data are narrated with detailed description, whereas in quantitative research, statistical procedures are used to describe statistical analysis (ibid:139).

In the current study, a large number of animal proverbs are selected and then they are delimited to 40 animal proverbs (qualitative approach). Accordingly, the research begins with qualitative data, and then, it tries to quantify them.

Moreover, Saville-Troike (2003, p. 95) indicates that it is profitable to use a mixture of both approaches because both approaches help to validate each other.

A quantitative method is used in addition to the qualitative one since the aim of the present study is to measure the effect of certain social variables on the use of animal proverbs and due to the insufficient nature of the qualitative approach to meet the research questions. It can be done through statistical analysis of the questionnaire. Jaber (2012, p. 74) ensures that such quantitative method can be used in response to variational research questions of social variables within the research.

To sum up, Richards and Schmidt (2002, p. 265) make the difference clear when they say that the qualitative research utilizes method which uses non-numerical data such as interviews or the researcher's observation, on the other end of the scale, quantitative approach refers to researches which collect and analyze data in a numerical form through tools such as experiments.

This research starts as qualitative concerning selecting and arranging the data. It is also qualitative in showing the cultural interpretations in the analysis of proverbs in detail. Besides, it is quantitative in showing statistically the frequencies of similarities and differences between the effects of social variables on the use of animal proverbs between the two cultures.

The administration of the test for the present study was done in May and June 2018. Informants are asked to seriously respond to the items of the test through explaining the importance of the project they are involved in. Such information is mentioned in the consent form in the survey. By having copies printed, test takers could complete the mission.

The test is managed using the following steps:

1. Conducting a questionnaire by adapting AmbuSaidi (2010) one.

2. Consulting certain experts to examine the validity of the questionnaire and making the necessarily amendments.

3. Copies are distributed to the testes (university students).

4. The time devoted to the test is $10-20 \mathrm{~m}$

5. The researcher distributes and collects the printed copies of the Iraqi samples himself and other MA students. The English questionnaires are distributed by the help of Asst. Prof. Fuad Jasim Mohammed (PhD Candidate at Leeds University), and Israa Hussein and her friend Faisal (students enrolled at London School of Economics and Political Sciences) who volunteer to help the researcher in conducting the test.

\section{DATA RELATED TO HORSE PROVERBS}

This group of the data is related to proverbs containing words referring to horse. It consists of the discussion of the English and the IA horse proverbs in isolation. Then, they are compared using the results of the statistical analysis.

\section{A. English Horse Proverbs Presentation}

The following Table I presents the four English horse proverbs which are extracted randomly from the given resources.

TABLE I

English Horse Proverbs

\begin{tabular}{ll}
\hline \hline No. & Horse proverbs \\
\hline a. & The gray mare is better than horse (FFDP, 2007: 110). \\
b. & If you cannot ride two horses at once, you should not be in \\
& the circus (OCDP, 2003:273). \\
c. & Never look a gift horse in the mouth (ODP, 2008:211). \\
d. & You can take a horse to water, but you cannot make \\
& him drink (OCDP, 2003:90). \\
\hline \hline
\end{tabular}

English Horse Proverbs Discussion

The horse has an important value in many cultures including the English. It is generally used as a symbol of power and independence. Obviously, people employ colorful examples from their environment to enrich their linguistic expressions (for example, the image of horse in proverbs) as shown in the after-mentioned proverbs.

The first given proverb literally means that the female gray horse "mare" is better than the male horse. This is taken from their everyday observation and it is reflected 
in proverbs. According to Leech's (1989) model, the important thing here is the connotative meaning of words or expressions. In fact, a language is symbolic. Thus, proverbs usually imply meaning other than their conceptual meaning. Accordingly, it implies that the human female is better than the human male. This proverb reveals cultural information about the modern place of woman in English. She is not only equal to men, but she is even more competent and powerful than him, you should not be deceived by the appearance or the gender of the other party. There is a French proverb used frequently in IA which is related to the same "وراء كل رجل عظيم امرأة" meaning with slight difference" (Behind every great man, there is a woman). This proverb praises the place of woman in Iraqi culture in that the men owe their success to the support of their women. The IA proverb shows the importance of woman in her social role but not to the extent that she is better than men as implied in the previous English proverb.

The second proverb means that if you do not have the required skill to ride two horses at the same time, you should not be in the circus. That is because the circus requires certain skillful people to do the risky tricks. This proverb presents the general principle that advises people to measure their skills and match them with the offered job. If they do not fit, they should retreat. They should not live beyond their available means and become just like dreamers. Otherwise, they will face many troubles because they are unqualified to do the offered job. It is similar to the English proverb "If you can't run with the big dogs, stay under the porch" (OCDP, 2003, p. 273). The implied advice presented in the given proverb is similar to that presented in the Iraqi proverb "كلمن يمد رجلية على كد لحافه" (Each one should stretch his feet according to the measurement of his coverlet). This teaches people to live with their available resources and avoid dreaming of the impossible by putting themselves in inappropriate places.

The third proverb presents advice taking a colorful image from their sociogeographic environment. It means literally that when you are given a horse as a gift, you should not look at its teeth to check if it has shortages or not. It is traditionally part of the English etiquette to accept gifts with gratitude. The proverb makes reference to the exercise of defining the horse's age by taking a look at its teeth. The older the horse is, the more it is worthless. This proverb implies a warning against questioning the quality of the opportunity offered to you by others. Otherwise, you will lose it as implied by other proverbs like "Opportunities knocks but once" (Siefring, 2004, p. 209). Obviously, every rule has exceptions. In some situations, one has to question the gift and "look at the gift horse in the mouth." Moreover, it is sometimes wiser to be doubtful about something offered by people whom you do not trust well. This coincides with the English proverb "Beware of Greeks bearing gifts" (FFDP, 2007, p. 26), with its historical famous story of deceiving that the Greek was capable of winning one of the bottles by deceiving their enemies with a gift made of a large horse made of wood known as "Trojan Horse."

\section{Sociolinguistic Variables and English Horse Proverbs}

Obviously, the characteristics of an animal (for example, horse) are reflected in proverbs to comment indirectly on human traits. The nature of such characteristics has, to some extent, an influence on their use by language user. The following Table II presents the relationship between the social factors and the use of horse proverbs.

TABLE II

The Co-occurrence of English Horse Proverbs with Social Variables

\begin{tabular}{lllcc}
\hline \hline No. & Social variable & $\begin{array}{l}\text { Factors of value } \\
\text { higher than } 25.00\end{array}$ & Mean & $\begin{array}{c}\text { Standard } \\
\text { deviation }\end{array}$ \\
\hline 1. & Cultural variables & Positive & 25.50 & 10.25 \\
2. & Occupational variable & Farmer & 34.50 & 3.79 \\
3. & Social distance variable & Remote & 29.50 & 1.91 \\
4. & Formality variable & Informal & 32.00 & 4.90 \\
\hline \hline
\end{tabular}

The mean scores given above indicate that the horse proverbs have positive connotations. Conventionally, the horses were the means of transportation for the English. Nowadays, they are used in farms by farmers and the like to help them accomplish their jobs. Such an animal is usually known by the English as powerful and independent. Among the given occupation, the animal proverbs are mainly used by farmers and the like of the same social status. This is because the lower social status people are less influenced by the development and they live in tight speech communities. Thus, they frequently use such animal proverbs because they tend to keep the cultural tradition. As indicated by Holmes (2013), the nature of the social relationship between speakers influences their use of the linguistic expressions. Accordingly, the study subjects indicate that the horse proverbs are among those linguistic expressions which are used among the participants of unequal relationship (for example, a boy to stranger, a man to police officer, and the like). Moreover, such horse proverbs are mainly used in informal interactions (for example, at homes or in the street).

\section{B. IA Horse Proverbs Presentation}

The following table shows the four IA horse proverbs which are selected randomly from the given written resources. 
TABLE III

IA Horse Proverbs

\begin{tabular}{|c|c|}
\hline No. & Horse proverbs \\
\hline \multirow[t]{2}{*}{1.} & (At-Tikriti, Vol. 1, 1971, p. 54). \\
\hline & $\begin{array}{l}\text { (The cousin has the right to order [his female cousin] to get down of } \\
\text { the horse). }\end{array}$ \\
\hline \multirow[t]{2}{*}{2.} & اكْنَبْ من فَرَس الزركَه (At-Tikriti, Vol. 1, 1971, p. 80). \\
\hline & (More untruthful than a blue horse). \\
\hline 3. & $\begin{array}{l}\text { الفَرَسِ من خيّالها، والمَرَه مِن رجَالْها (At-Tikriti, Vol. 3, 1981, p. 590). } \\
\text { (The behavior of the horse is determined by its rider and the wife by } \\
\text { her husband). }\end{array}$ \\
\hline 4. & 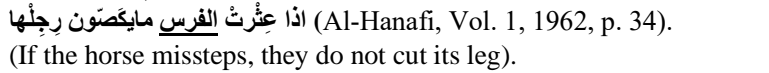 \\
\hline
\end{tabular}

IA Horse Proverbs Discussion

Horses have a remarkable place in the traditional life of Iraqi tribes. They enrich the language of Arabs with colorful images such as those found in the aftermentioned proverbs.

The first proverb in Table III has the meaning of the cousin's tribal lawfulness. He can command his female cousin to get down of the horseback when she sets off to her newly bridegroom's house. This reflects the Iraqi's historical cultural norms that the bride goes to her bridegroom's house on the back of a horse during the wedding party. The cousin has the right to reject the espousal because traditionally, he has the right over others in getting his female cousin's hand. On the one hand, the Iraqi tribes want to keep the structure of the tribal society. On the other hand, they want to give their girls to those whom they know well because they do not trust the ones whom they do not know well as reflected in the following saying "اللي نعرفه أحسن من اللي ما نعرفه" (the one whom we know well is better than the one whom we do not know). It is somehow against the instructions of Islam which encourages men not to ask the hand of their relatives for certain genetic purposes. The implied meaning of this proverb is that some people have the right over others in doing something. It can be applied to various situations whenever one feels that he is more deserving than the others in doing something. Moreover, the horse in the given proverb is associated with nobility because it is chosen among other animals to transport the bride on its back.

By contrast, the horse is portrayed differently in the second proverb. It means literally that one lies more than the blue horse does. This comparison comes from the behavior of the Arab blue horse. Riders of the blue horse claim that if the blue horse does not want to go out at night, it makes signals like raising its head or ears. Such signals are understood by its rider that there is danger near them such as wild animals or the like. Consequently, the rider decides to retreat. Later on, the rider discovers that the blue horse cheated him that there is no threat around. This proverb is familiar in the rural areas, particularly to the Bedouins. Its implied meaning is that some people are highly associated with the property of lying. The blue horse's bad characteristics are used to criticize the negative human traits of lying.

The third proverb associates the behavior of woman with that of the horse. It says that the horse is clever enough to know its rider. If he is determined and strong, it will take him to his destination easily. Moreover, if he is not, it will refuse to obey him. It may hardly drive him to his destination and it may drop him out of its back. The same can be applied to wives as claimed by the given proverb with analogy to the horse's behavior. According to the Iraqi culture, the good husband can control the behavior of his wife right from the beginning. He can direct her to the right track. Otherwise, some of the wives may try to have control over their husbands to the extent that the husband cannot get her back to his obedience. This proverb has a social message that some women are arrogant. It is the role of their husbands to control them right from the beginning. This proverb is similar to the American proverb "A good Jack makes a good Jill" (RBWP, 2006, p. 227), which describes the relationship between husbands and wives that the good husbands make good wives. It is also similar to the English proverb "The calmest husbands make the stormiest wives" (ibid) that some husbands' behavior leads the wives to be stubborn and disobedient to him.

However, the fourth proverb associates the horse with nobles and good people. The proverb shows that if the horse missteps, they should forgive it. It implies that some good people commit mistakes. This unintended behavior must be forgiven by others because their good intention should be understood by others. It is similar to the classical Arabic proverbs "لكل جواد كبوة" (Cited in Sameer, 2016, p. 140), (every horse may misstep). It is also similar in meaning to the modern proverb which "كل ابن ادم خطّاء" goes back to the prophetic tradition (Every human commits mistakes). The implied meaning of the given fourth proverb indicates that the mistakes of the good people should be excused. The English proverbs which express similar meaning are "Nobody is infallible" (RBWP, 2006, p. 167) and to "To err is human" (ibid:276).

\section{Sociolinguistic Variables and IA Horse Proverbs}

People have to make many choices when interacting using language. They feel that the language they use reflects their social identity. The language of the shepherd is not like that of the educated man. They also know the rule which says " لكل مقام مقال " (language choice is dependent on the situation), whether they are in formal or informal interactions. That is why the use of horse proverbs is frequently used with certain social 
variables rather than others as shown in the following table:

TABLE IV

The Co-occurrence of IA Horse Proverbs with Social Variables

\begin{tabular}{lllcc}
\hline \hline No. & Social variable & $\begin{array}{l}\text { Factors of value } \\
\text { higher than 25.00 }\end{array}$ & Mean & $\begin{array}{c}\text { Standard } \\
\text { deviation }\end{array}$ \\
\hline 1. & Cultural variables & Positive & 34.50 & 13.48 \\
2. & Occupational variable & Farmer & 26.00 & 8.98 \\
3. & Social distance variable & Close & 33.75 & 6.29 \\
4. & Formality variable & Informal & 34.75 & 5.38 \\
\hline \hline
\end{tabular}

The mean scores of the social variables are stated in Table IV reveal a lot of information about the way such proverbs are frequently used. The Arabs in general including the Iraqis have been looking at the horse positively as a symbol of power and nobility. Indeed, such symbol becomes an important motif when Iraqi speakers use the language in their daily interactions. This attitude is proved by IA study subjects' recognition that the proverbs containing "horse" have positive connotations. Moreover, since the majority of the Iraqis no longer use horse for the same traditional purpose, it leads to constraint in the use of horse proverbs in the sense that they are frequently used by lower status people (for example, farmers, shepherds, etc.). It is undoubtedly that the recent prestigious way of life has been changed. Conventionally, the prestigious status of a man is related to his property of horses and his horsemanship is an important factor in the man's social life. In recent days, it is different in that people may only see horses in Zoos and some other places. This change of lifestyle results in the association of the use of horse proverbs only when the participants are socially familiar to each other (that is, having solidarity). According to Holmes' (2013) model of the social variables, the formality dimension accounts for the variation of speech in accordance with different social contexts. Certain interactions require the choice of appropriate language expressions including proverbs. In the present study, it is apparent that the horse proverbs are associated with the informal interactions as emphasized by the study subjects.

\section{Comparison of the Effect of Social Variables on Horse Proverbs Groups}

The following Graph 1 shows the mean scores of the social factors related to the English and the IA horse proverbs.

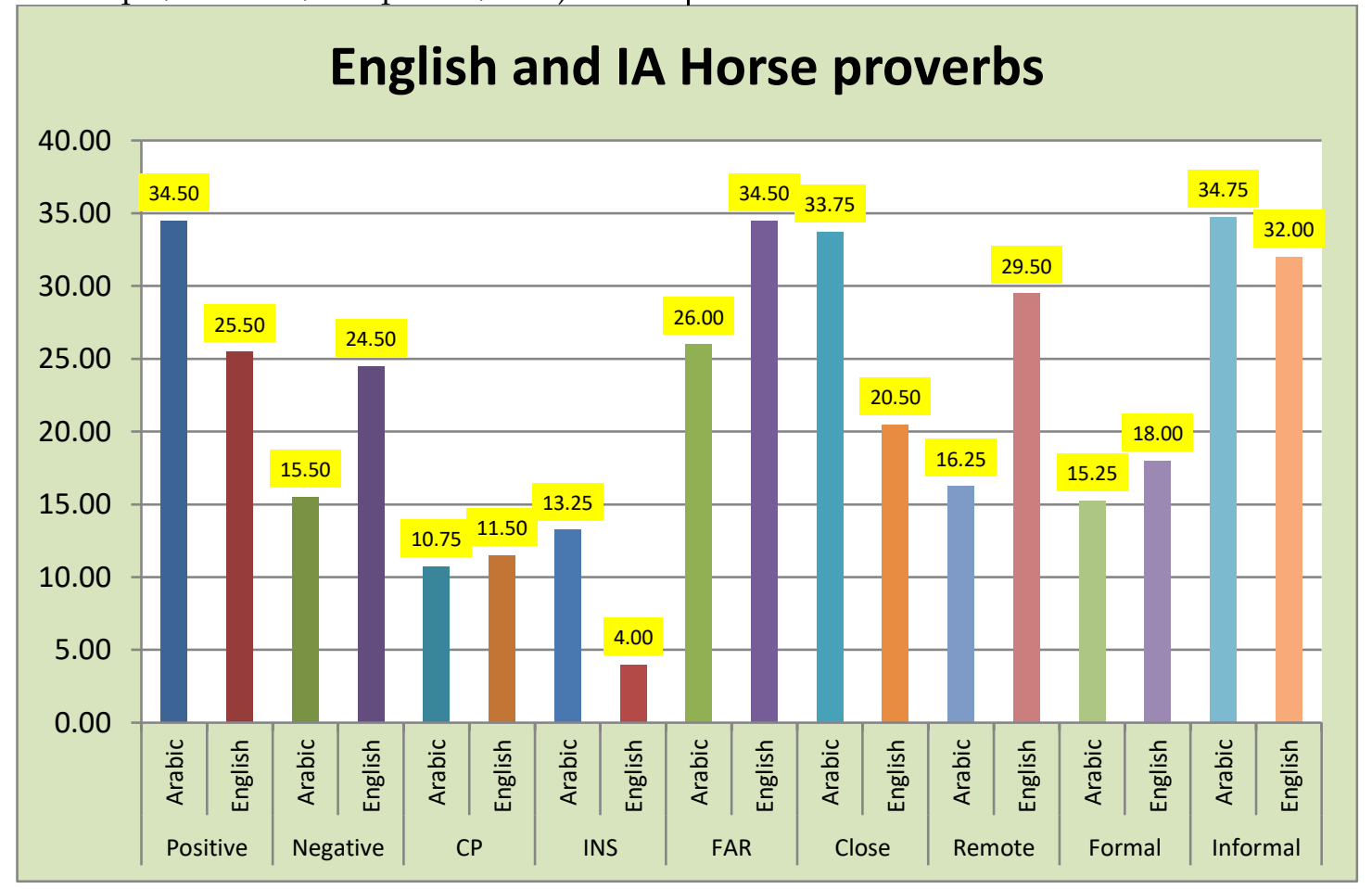

The different culture's attitudes toward horses and the different routines of people result in the variations between the interaction of the social variables and the use of proverbs with "horse" as a protagonist. Having applied t-test formula, it is found that there are significant differences between the recognition of the English group and that of the IA study subjects with

their own proverbs. It is figured out that there are significant differences at the level of 0.01 of significance related to the occupational and the social distance variables among the English and the IA group. First, IA instructors at high school tend to use horse proverbs more than the English ones as recognized by the study subjects. It is due to the attitudes of the IA instructors 
about the place of the horse in the society which has been traditionally associated with the status of men. Despite being eventually vanished, this fact still has some influence on IA professionals more than it does to the English ones. In addition, there are also significant differences between the two groups in the close social variable to the advantage of the IA group. It is obvious that the IA group more heavily uses horse proverbs when there is intimacy between participants than the English do. In reverse, there is a significant difference between the remote variable of the two groups. It is predicted by the study subjects that the English tends to use horse proverbs with people who are socially distant (employee to his superior) than the IA do.

\section{FINDINGS AND CONCLUSIONS}

Throughout the analysis in this research, it is concluded that:

1. Concerning the social variable, both English and IA testes show positive value in relation to most of the analysed proverbs.

2. The occupational variable shows that native speakers of both languages indicate that the proverbs which include the horse image are used more frequently by farmers other than other occupations.

3. The social distance variable is highly remote in English and it is close in IA.

4. In languages, the proverbs which contain the horse image are used more frequently in informal situations as it is indicated by the results of the questionnaire.

5. Although the analysed proverbs may have different stories and they seem different in meaning, most of them share similar topics and connotations.

\section{REFERENCES}

Al-Hanafi, J. (1962) Al-amtha: 1 al-baghda: diya. Vol. 1. Baghdad: Maktabat Al-Muthnna.

Ambu-Saidi, S. (2010) Gender and Langage Analysis of Omani Proverbs. (Unpublished MA Thesis). University of Florida.

At-Tikriti, A. (1971) Jamhrat al-amtha: 1 al-baghda: diah. Vol. 1. Baghdad: Matb?at Al-?irsa: d.

At-Tikriti, A. (1981) Gamhrat al-amtha: L al-Baghda: Diah. Vol. 3. Baghdad: Da: r Al-Huriyah Lil-tiba:Sah.

Best, J.W. and Kahn, J. (2006) Research in education. New Delhi: Prentice Hall of India Pvt. Ltd.

Holmes, J. (2013) An introduction to sociolinguistics. 4th ed. London: Longman Group.
Jaber, R.S. (2012) Gender and Age Effects on Lexical Choice in the Baghdadi Speech Community: A Cognitive Sociolinguistic Analysis (Unpublished PhD Thesis). University of Utra Malysia.

Leech, G. (1981) Semantics: The study of meaning. 2nd ed. London: Richard Clay Ltd.

Manser, M.H. (2007) In: Ferguson, R. and Pickering, D., (eds.), The facts on file dictionary of proverbs (FFDP). 2nd ed. New York: An Imprint of Infobase Publishing.

Moini, M.R. (2008) Research methods and designs in humanities. University of Kashan: Jungle Publication.

Richards, J.C. and Schmidt, R. (2002) Longman dictionary of language teaching and applied linguistics. 3rd ed. Malaysia: Pearson Education Limited.

Sameer, I.H. (2016) A cognitive study of certain animals in English and Arabic proverbs: A contrastive study. International Journal of Language and Linguistics, 3(5), pp. 133-143.

Saville-Troike, M. (2003) The ethnography of communication: An introduction. 3rd ed. Oxford: BlackWell.

Siefring, J., (ed.) (2004) Oxford dictionary of idioms. 2nd ed. Oxford: Oxford University Press.

Simpson, J. and Speake, J., (ed.). (2003) The Oxford concise dictionary of proverbs (OCDP). Oxford: Oxford University Press.

Speake, J. and Simpson, J., (eds.). (2008) The Oxford Dictionary of Proverbs (ODP). 5th ed. Oxford: Oxford University Press.

Stone, J.R., (ed.). (2006) The Routledge book of world proverbs (RBWP). Oxon: Routledge, Taylor and Francis Group.

Yule, G. (2010) The study of language. 4th ed. Cambridge: Cambridge University Press 